Abant Tıp Dergisi

Olgu Sunumu / Cilt 9 Sayı 2 Yıl 2020
Abant Medical Journal

Case Report / Volume 9 Issue 2 Year 2020

\title{
Budd-Chiari Sendromu ile Prezente Olan Ampulla Vateri Tümörü
}

Tumor of the Ampulla of Vater Presented with Budd-Chiari Syndrome

Fatıma Nur Kozhan ${ }^{1}$ (D) , Tezcan Kaya ${ }^{2}$, Esma Seda Çetin ${ }^{1}$ iD , Döndü Ayvalık ${ }^{1}$ iD , Alper Karacan ${ }^{3}$ iD

${ }^{1}$ Sakarya Üniversitesi Eğitim ve Araştırma Hastanesi, İç Hastalıkları Kliniği, Sakarya, Türkiye

${ }^{2}$ Sakarya Üniversitesi Tıp Fakültesi, İç Hastalıkları Anabilim Dalı, Sakarya, Türkiye

${ }^{3}$ Sakarya Üniversitesi Tıp Fakültesi, Radyoloji Anabilim Dalı, Sakarya, Türkiye

\section{Öz}

Budd-Chiari sendromu hepatik venöz çıkış yolunun tromboz veya flebit nedenli obstrüksiyonu ile oluşan nadir bir klinik tablodur. Etyolojisinde venöz dönüşü bozan hastalıklar, tromboza eğilim yapabilen durumlar veya vaskülit nedenleri yer almaktadır. Ampulla vateri adenokarsinomu gastrointestinal sistem malignitelerinin oldukça az görülen bir tümörüdür. Ampulla vateri tümörünün başlangıç aşamasında Budd-Chiari sendromuna neden olması ve birlikteliği nadir bir durumdur. Bu makalede asit, ikter nedeni ile yatırdığımız ve ampulla vateri tümörüne bağlı Budd-Chiari sendromu tanısı koyduğumuz bir olgu sunulmuştur.

Anahtar Kelimeler: Ampulla Vateri, asit, Budd-Chiari Sendromu, tromboz

\section{Giriş}

Budd-Chiari sendromu (BCS) hepatik venöz çıkış yolunun tromboz veya flebit nedenli obstrüksiyonu ile oluşan nadir bir klinik tablodur (1). BCS tanısı için venöz dönüşü bozabilen kalp hastalığı, perikard hastalığı ve veno-okluziv hastalık olmaması gerekmektedir (1). Hepatik ven ve/veya vena kava inferiora bası veya invazyon yapan malignite gibi bir patoloji varsa sekonder BCS başlığı altında yer alır. Bu gibi durumların dışında gelişen tüm tromboz olayları ise primer BCS olarak adlandırılmaktadır. Hastalarda klinik belirti ve bulgu olarak akut karaciğer yetmezliği, ateş, karın ağrısı, ikter, hepatik ensefalopati, asite bağlı karında distansiyon ve alt ekstremitelerde ödem görülebilir (1-3). BCS nedenleri arasında miyeloproliferatif hastalıklar, malignite, herediter trombofili varlığı, oral kontraseptif kullanımı, Behçet hastalı̆̆ı, karaciğerde yer

\section{Abstract}

Budd-Chiari syndrome is a rare clinical condition that characterized with hepatic venous outflow tract obstruction caused by thrombosis or phlebitis. Etiology includes diseases that disrupt venous return, conditions that can predispose to thrombosis, or causes of vasculitis. Adenocarcinoma of the ampulla of Vater is a rare tumor of gastrointestinal malignancies. It is very rare for tumor of the ampulla of Vater to cause and coexist with Budd-Chiari syndrome in its initial stage. In this article, we presented a case of Budd-Chiari syndrome associated with tumor of the ampulla of Vater which we were hospitalized due to ascites and icter.

Keywords: Ampulla of Vater, ascites, Budd-Chiari syndrome, thrombosis

kaplayan bazı lezyonlar ve enfeksiyonlar gibi farklı klinik durumlar bildirilmiştir $(2,3)$.

Ampulla vateri adenokarsinomu gastrointestinal sistem malignitelerinin \% $0,2^{\prime}$ si oranıyla oldukça az görülen bir tümördür (4). Hastalarda genellikle kilo kaybı, karın ağrısı, safra yollarının tıkanması sonucunda ağrısız sarılık, kolanjit ve pankreatik kanalın tıkanması nedeniyle de rekürren pankreatit atakları görülebilmektedir (4-6). Ampulla vateri tümörünün başlangıç aşamasında BCS'ye neden olması ve birlikteliği oldukça nadir bir durumdur. Bu makalede asit, ikter nedenli yatırdığımız ve yapılan tetkikleri sonucu ampulla vateri tümörüne bağlı BCS tanısı koyduğumuz bir olgu sunulmuştur. 


\section{OLGU SUNUMU}

79 yaşında kadın hasta yaklaşık 10 gündür olan karın ağrısı, karında şişlik ve sarılık şikâyetleri ile hastanemiz dahiliye polikliniğine başvurdu. Özgeçmişinde hipertansiyon dışında özellik yoktu. Devamlı kullandığı ilaç olarak sadece antihipertansif irbesartan vardı. Alışkanlıklarında sigara, alkol, bitkisel madde kullanımı yoktu. Muayenesinde şuuru açık, oryantasyon ve kooperasyonu tam idi. Tansiyon arteryeli 100/60 $\mathrm{mmHg}$, nabzı 83 vuru/dakika ritmik, ateş 36,5 ㅇ saptandı. Skleraları ve tüm vücut ikterik görünümdeydi. Batın muayenesinde açıklığı yukarı bakan, yer değiştiren asit ile uyumlu matite mevcuttu. Traube alanı açıktı. Diğer sistem muayenelerinde belirgin özellik yoktu. Laboratuvar tetkiklerinde lökosit $9700 \mathrm{~K} / \mathrm{ul}$, hemoglobin $11,8 \mathrm{~g} / \mathrm{dl}$, trombosit $209000 \mathrm{~K} / \mathrm{ul}$, üre $31 \mathrm{mg} / \mathrm{dl}$, kreatinin $0,9 \mathrm{mg} / \mathrm{dl}$, ürik asit 3,2 $\mathrm{mg} / \mathrm{dl}$ ALT $53 \mathrm{U} / \mathrm{L}$, AST $154 \mathrm{U} / \mathrm{L}, \mathrm{GGT} 845 \mathrm{U} / \mathrm{L}$, alkalen fosfataz $680 \mathrm{U} / \mathrm{L}$, total bilirubin $3,4 \mathrm{mg} / \mathrm{dl}$ direk bilirubin $1,9 \mathrm{mg} / \mathrm{dl}$, LDH $275 \mathrm{U} / \mathrm{L}$, total protein $5,5 \mathrm{~g} / \mathrm{dl}$, albümin $2,5 \mathrm{~g} / \mathrm{dl}$, sodyum 141 $\mathrm{mmol} / \mathrm{L}$, potasyum $3,7 \mathrm{mmol} / \mathrm{L}$, kalsiyum 7,7 $\mathrm{mg} / \mathrm{dL}$ idi. Hasta asit-ikter etiyolojisinin araştırılması amacıyla iç hastalıkları servisine yatırıldı. Parasentezle aldığımız asit sıvısı örneği tetkiklerinde glukoz $126 \mathrm{mg} / \mathrm{dl}, \mathrm{LDH} 53 \mathrm{U} / \mathrm{L}$, albümin $0,6 \mathrm{gr} / \mathrm{dl}$, protein $1,3 \mathrm{gr} / \mathrm{dl}$ idi. Asit sıvısI hücre sayımında lökosit yoktu. Serum-asit albumin gradienti 1,9 olarak hesaplandı ve bu nedenle portal hipertansiyon yapan nedenler düşünüldü. Viral hepatit belirteçlerinden $\mathrm{HbsAg}$ ve Anti-HCV negatif saptandı. Asit sıvısının sitolojik incelemesi bening olarak raporlandı ve asit sıvısı kültüründe üreme olmadı. Utrasonografide karaciğer uzun aksı 175 mm karaciğerin konturu, parankim dansitesi doğal, intrahepatik safra yolları dilate, proksimal koledok 22,5 mm, dalak büyüklüğü normal, batında yaygın asit olarak görüldü. Kalp yetmezliği veya kalp kapak hastalığı açısından yapılan ekokardiyografik değerlendirmede ejeksiyon fraksiyonu ve kapaklar normal bulundu. Portal ven doppler ultrasonografide portal ven çapı $13 \mathrm{~mm}$, akım yönü karaciğere doğru, lümen içi tromboz saptanmadı. Batın bilgisayarlı tomografide intra ve ekstrahepatik safra yollarında dilatasyonu, koledoğun duodenuma açıldığı lokalizasyonda kontrast tutulumu gösteren kitlesel lezyon ve batın içi yaygın serbest sıvı izlendi (Şekil 1). Kolestazı ve safra yollarında dilatasyonu olan hastaya dinamik manyetik rezonans (MR) ve manyetik rezonans kolanjiopankreatografi (MRCP) çekimi yapıldı. Dinamik MR'de vena cava karaciğerden itibaren iliak bifurkasyona kadar tromboze görünümde, distalinde tabii olarak izlendi, koledok çevresinde düzensiz kitle formasyonu izlendi (Şekil 2). MRCP'de intrahepatik safra yolları ileri derecede ektazik, koledok vater papillasından başlayan süperiora doğru uzanım gösteren ılımlı kontrast tutan kitle formasyonu, vater papilla kitlesi veya klatskin tümör ile uyumlu olabilir şeklinde yorumlandı. Malignite şüphesi olan hastanın tümör belirteçleri CEA 3,6 $\mu \mathrm{g} / \mathrm{L}, \mathrm{CA} 1251302$ $\mathrm{U} / \mathrm{ml}$, CA 19-9 $147 \mathrm{U} / \mathrm{ml}$, AFP 1,3 ng/ml idi. Hepatik ven-vena kava trombozu için damar cerrahisi invaziv cerrahi girişim düşünmedi, düşük molekül ağırlıklı heparin önerdi. Gastroenteroloji tarafından yapılan endoskopik ultrasonografi ile periampuller bölgeden alınan biyopsi adenokarsinom olarak raporlandı. Ampülla vateri adenokarsinomu tanısı koyulan hasta operabilite açısından genel cerrahionkoloji-radyoloji konseyi tarafınca değerlendirildi ve inoperabl kabul edildi. Hasta gastroenteroloji ve onkoloji poliklinik kontrolleri önerilerek taburcu edildi. 


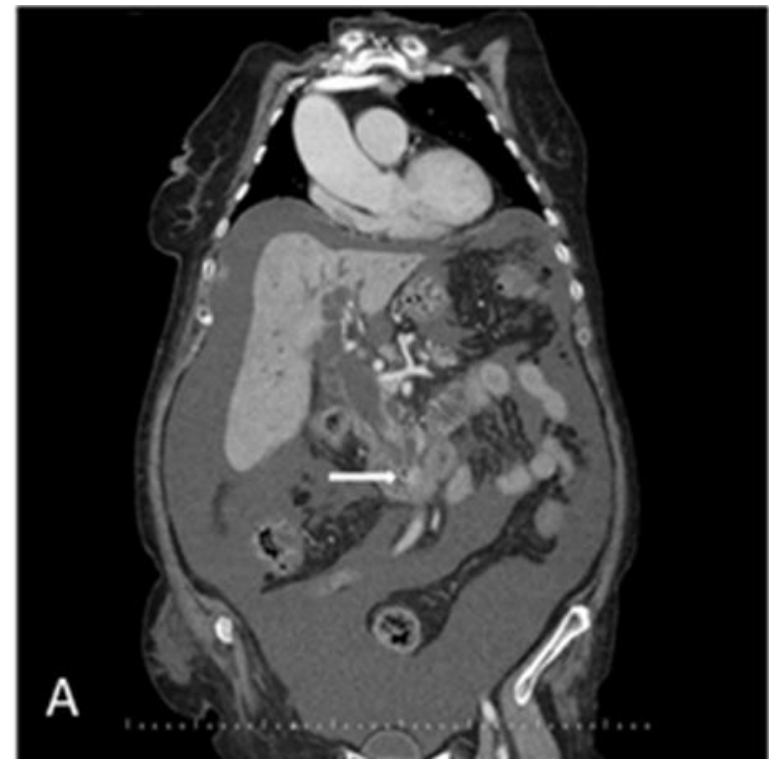

Şekil 1. Koronal plan kontrastlı bilgisayarlı tomografi görüntüsünde intra ve ekstrahepatik safra yollarında dilatasyonu ile birlikte koledoğun duodenuma açıldığı lokalizasyonda kontrast tutulumu gösteren kitlesel lezyon izlenmektedir.

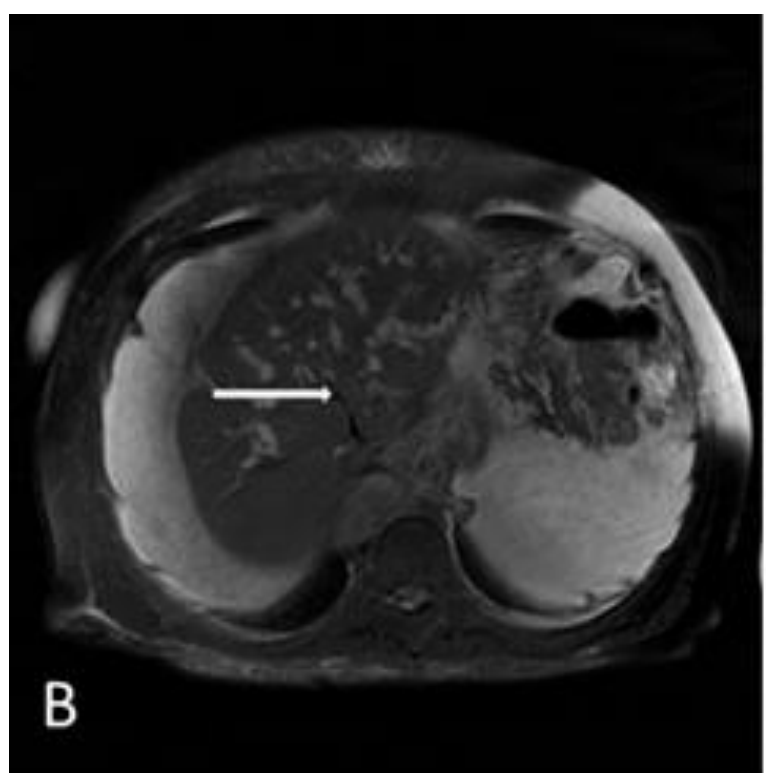

Şekil 2. Aksiyel plan T2 sekans manyetik rezonans görüntüsünde intrahepatik safra yollarında dilatasyon ile birlikte vena cava inferiora açılan orta hepatik ven izlenmektedir. Sağ ve sol hepatik venler oklüde görünümdedir.

\section{TARTIŞMA}

BCS' de hepatik venin farklı nedenlere bağı olarak tıkanması sonucu karaciğer çıkışındaki vasküler yapıda obstrüksiyon mevcuttur (1). Olguların yaklaşık \% 20'sinde etyoloji ortaya koyulamaya bilmektedir (1,2). Tromboz riskini artırarak
BCS'na yol açabilen durumlardan bazıları kronik miyeloproliferatif hastalıklar (özellikle polistemia vera ve esansiyel trombositemi), oral kontraseptif kullanımı, gebelik, herediter trombofili varlığı ve bazı malignitelerdir $(2,3)$. Diğer BCS nedenleri olarak sarkom, renal veya adrenal tümörler, hepatoselüler karsinom, hidatik kist-abse gibi karaciğer enfeksiyonları, Behçet hastalı̆̆ı, radyoterapi ve karaciğer travmaları bulunur $(2,3)$. Bizim hastamızda olduğu gibi ampulla vateri adenokarsinomunun tanı aşamasında BCS olması oldukça nadir olup literatür araştırmamızda benzer olgu bulamadık. Sunduğumuz olguda BCS'nun maligniteye bağlı salgılanan sitokinlerin stimülasyonu ile ortaya çıkan hiperkoagülabl durum ile ilişkili olabileceğini düşünmekteyiz. Literatürde özellikle hepatoselüler karsinomun ilk bulgusu olarak çok sayıda BCS olgusu bildirilmiştir (7).

BCS gelişen hastalarda görülebilen başlıca klinik belirti ve bulgular karın ağrısı, ateş yüksekliği, alt ekstremitelerde ödem, asit ve ikterdir $(5,6,8)$. Ayrıca portal hipertansiyona sekonder gelişen özofagus varisi veya portal hipertansif gastropatiye bağlı kanama, hepatik ensafalopati de görülebilir $(5,6,8)$. Primer hastalığa bağlı örneğin kilo kaybı, kaşeksi gibi farklı belirti ve bulgular da olabilir $(5,6,8)$. Bizim hastamızda da kilo kaybı, ikter ve portal hipertansiyon ilişkili asit mevcuttu.

BCS tedavisinde pıhtının artmasını önleme amaçlı antikoagülan tedavi; tromboze venin rekanalize olabilmesi için trombolitik tedavi, anjoplasti/stent uygulanmasl; portal hipertansiyon-asit varsa transjuguler intrahepatik portosistemik şant, cerrahi şantlar uyulanabilmektedir $(1,2,8)$. Ayrıca tedavide bazı hastalar için (fulminan BCS gibi) karaciğer tranplanstayonu da yapılabilir $(1,2,8)$. Fakat asıl tedavi altta yatan primer hastalığın tedavisidir.

Vater ampullası (ampulla, major papilla) duodenum duvarında pankreatik ve biliyer kanalların birleştiği bölgede bulunur. Primer 
ampüller tümörler oldukça nadir görülmekte olup insidansı yaklaşık olarak milyonda 4-6'dır $(5,6)$. Hastalık kendisini hastalarda ilk planda \%80 oranıyla daha çok obstrüktif ikter olarak gösterir $(5,6,9)$. Üst gastrointestinal sistem kanaması, karın ağrısı, bulantı, ishal, kilo kaybı ve halsizlik de görülebilir $(5,6,9)$.

Ampulla vater tümörü tedavisi hastalığın evresine, hastanın komorbid hastalıkları ve genel performans durumuna göre belirlenmektedir $(4,6)$. Cerrahi tedavi olarak yapılabilen prosedürler lokal transduodenal rezeksiyon, pankreotikoduodenektomi (Whipple ameliyatı) ve pankreas koruyucu duodenektomidir $(5,6,9)$. Lokal ve sınırlı kitle varlığında endoskopik olarak rezeksiyon ve lazer ablasyon yapılabilmektedir $(5,6,9)$. Kemoteropi ve radyoterapi de hastalığın evresine göre tedavi seçeneklerindendir $(5,6,9)$.

Sonuç olarak asit, ikter ve karın ağrısı olan hastalarda neden olarak BCS olabileceği akılda tutulmalıdır. Ampulla vateri tümörü nadir bir bulgu olarak tanı aşamasında BCS'na neden olabilir. Ayrıca ampulla vateri tümörü olan olgularda BCS varlığı kötü prognoz ve inoperabilite için bir bulgu olabilir.

Bilgilendirilmiş Onam: Katılımcılardan yazılı onam alınmıştır.

Çıkar Çatışması: Yazarlar çıkar çatışması beyan etmemişlerdir.

Finansal Destek: Yazarlar finansal destek beyan etmemişlerdir.

\section{REFERENCES}

1. Valla DC. Budd-Chiari syndrome and veno-occlusive disease/sinusoidal obstruction syndrome. Gut 2008; 57(10): 1469-78.

2. Darwish Murad S, Plessier A, Hernandez-Guerra M, et al. Etiology, management, and outcome of the Budd-Chiari syndrome. Ann Intern Med 2009;151(3):167-75.

3. Wang ZG. Budd-Chiari syndrome. 430 case experiences. Asian J Surg 1996; 19: 23-30.

4. Albores-Saavedra J, Schwartz AM, Batich K, Henson DE. Cancers of the ampulla of vater: demographics, morphology, and survival based on 5,625 cases from the SEER program. J Surg Oncol 2009; 100(7): 598-605.

5. Yamaguchi K, Enjoji M. Carcinoma of the ampulla of vater.
A clinicopathologic study and pathologic staging of 109 cases of carcinoma and 5 cases of adenoma. Cancer 1987; 59(3): 506-15.

6. Beger HG, Treitschke F, Gansauge F, Harada N, Hiki N, Mattfeldt T. Tumor of the ampulla of Vater: experience with local or radical resection in 171 consecutively treated patients. Arch Surg 1999; 134(5): 526-32.

7. Bălăceanu LA, Diaconu CC, Aron G. Budd-Chiari syndrome as an initial presentation of hepatocellular carcinoma: a case report. Med Ultrason 2014; 16(2): 172-74.

8. Coilly $A$, Potier $P$, Broué $P$, et al. Budd-Chiari syndrome. Clin Res Hepatol Gastroenterol 2020 Apr 2. pii: S22107401(20)30090-5.

9. Zheng-Pywell R, Reddy S. Ampullary Cancer. Surg Clin N Am 2019;99(2):357-67. 